\title{
Corrosive and Mechanical Degradation of Pipelines in Acid Soils
}

\author{
L. Ya. Poberezhnyi, ${ }^{a}$ P. O. Marushchak, ${ }^{b, 1}$ A. P. Sorochak, ${ }^{b}$ D. Draganovska, ${ }^{c}$ \\ A. V. Hrytsanchuk, ${ }^{a}$ and B. V. Mishchuk ${ }^{a}$ \\ ${ }^{a}$ Ivano-Frankivsk National Technical University of Petroleum and Gas, Ivano-Frankivsk, Ukraine \\ b Ternopil Ivan Puluj State Technical University, Ternopil, Ukraine \\ c Technical University of Košice, Košice, Slovakia \\ ${ }^{1}$ Maruschak.tu.edu@gmail.com
}

The effect of in-service degradation on the deformation behavior of the material of gas mains in soil acid electrolytes has been studied, and it has been shown that depending on the concentration of the corrosive components of the environment, the strain increment can be up to 20-30\%. It has been found that in soil acid electrolytes, degraded pipeline steel shows a tendency to sudden strain jumps, which can cause spontaneous depressurization of the pipeline.

Keywords: main pipelines, corrosive and mechanical degradation, long operating age, deformation kinetics, localization of corrosion processes.

Introduction. Ukraine is a large-scope natural gas transit countries: by the gas main systems that are managed by the National Joint-Stock Company Naftohaz Ukrayiny, Russian natural gas comes to countries of Western, Central, and Eastern Europe. These systems are technologically connected with the analogous gas mains in Russia, Belarus, Moldova, Romania, Hungary, Slovakia, and Poland and through them with the gas pipelines of the whole European continent. The inlet capacity of the Ukrainian gas transportation system (GTS) is $290 \mathrm{bcm}$, and the outlet capacity (to countries of Western, Central, and Eastern Europe, as well as to Moldova and to the south of Russia) is almost $170 \mathrm{bcm}$ per year.

However, in recent years, reproaches as to the unreliability of the Ukrainian GTS owing to the exhaustion of the design service life by a large number of gas mains are heard increasingly often. However, the planned service life not always takes into account all degradation processes in the material of gas pipelines; therefore, the evaluation of the state of pipeline systems by the actual state came to be widely practiced.

Theoretical and experimental studies of the gegradation of the material of pipes showed changes in their physicomechanical characteristics, which are, however, not catastrophic, and their use under optimized operating conditions will make it possible to ensure the reliable operation of the Ukrainian GTS. Thus, the study of the behavior of pipe steels under the conditions of the long-term influence of operating environments to ensure the serviceability of pipelines is topical. To this end, a study of the synergistic action of the corrosion and mechanical factors has been carried out on model specimens cut out from the pipe wall.

An important stage of the study of the effect of operating age on the deformation behavior of the pipeline material is testing in soil acid electrolytes. The topicality of studying the effect of $\mathrm{pH}$ on the peculiarities of corrosion and mechanical processes is due to the fact that in Western Ukraine, where there are a considerable number of main gas and petroleum pipelines, acid soils with chloride and chloride-sulfate electrolytes are widespread [1]. It is known that the steels of long-operated pipelines are especially susceptible to hydrogen embrittlement, the risk of whose occurrence in the acid environments is the greatest.

(C) L. Ya. POBEREZHNYI, P. O. MARUSHCHAK, A. P. SOROCHAK, D. DRAGANOVSKA, A. V. HRYTSANCHUK, B. V. MISHCHUK, 2017 
Materials and Research Procedure. Gas mains of large diameter made of 19G steel, which have been operated for 41 years, were chosen as the object of our research. The chemical composition of the $19 \mathrm{G}$ steel is shown in Table 1 . This tube material that was widely used in the building of main pipelines in the 1970s, and it is used up to now. To carry out research, the main gas pipelines department Kyivtranshaz was given fragments cut out from the lower part of pipes from sections of the gas main Shebelinka-PoltavaKyiv (diameter $720 \mathrm{~mm}$, 19G steel, service time: 1963- 2004). The fragments of pipes in the as-delivered condition were given from the emergency reserve.

$\mathrm{T}$ a $\mathrm{b} 1$ e 1

Chemical Composition of 19G Steel (in \%)

\begin{tabular}{|c|c|c|c|c|c||}
\hline $\mathrm{C}$ & $\mathrm{Si}$ & $\mathrm{Mn}$ & $\mathrm{Ni}$ & $\mathrm{S}$ & $\mathrm{P}$ \\
\hline $0.16-0.22$ & $0.2-0.4$ & $0.7-1.0$ & up to 0.3 & up to 0.04 & up to 0.035 \\
\hline $\mathrm{Cr}$ & $\mathrm{N}$ & $\mathrm{Cu}$ & $\mathrm{As}$ & $\mathrm{Fe}$ & \\
\hline $0.8-1.15$ & up to 0.008 & up to 0.3 & up to 0.08 & $\approx 97$ & \\
\hline
\end{tabular}

Cylindrical model specimens of the length $l=100-150 \mathrm{~mm}$ and with the test portion diameter $d=5-10 \mathrm{~mm}$ were tested on a setup, whose peculiarities are described in [2]. Smooth solid (Fig. 1a, b) and tubular specimens with the zero length of the test portion, $l_{p}$, design stress raisers (Fig. 1c), and induced cracks, as well as special smooth cylindrical specimens with a blind axial hole and a cap, and insulating coatings for the simulation of the operation of a subsea pipeline with the transported product were investigated.

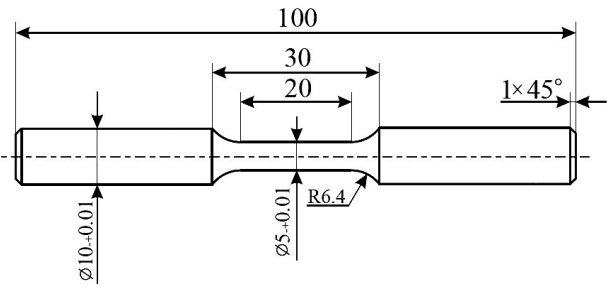

a

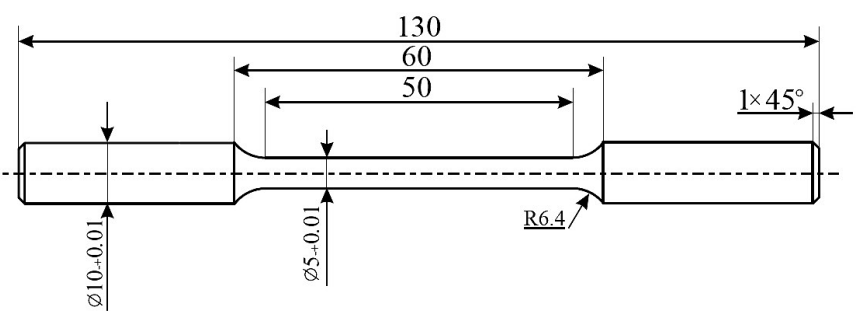

b

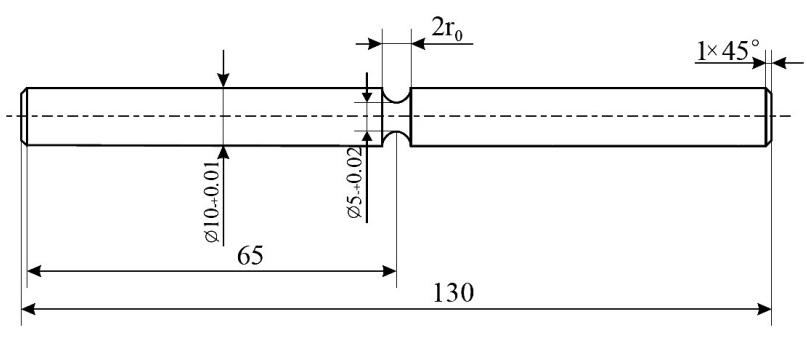

c 


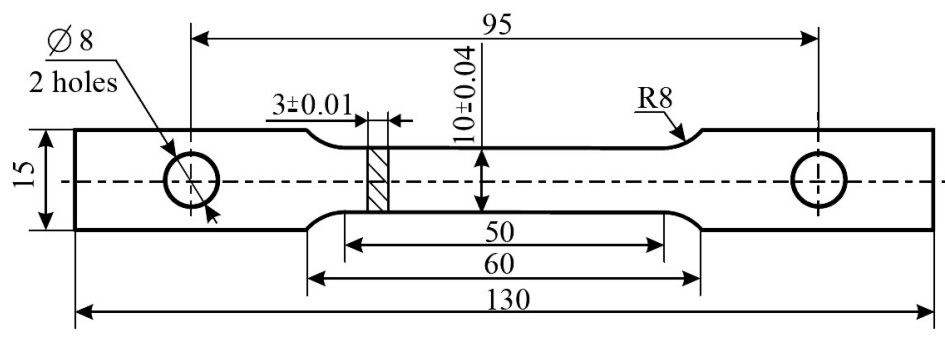

d

Fig. 1. Basic designs of model specimens for tests on the setups MV-1K $(a-c)$ and KN-1 $(d)$ : (a) short specimens $\left(l_{p} / d=4\right)$; (b) long specimens $\left(l_{p} / d=10\right)$; (c) specimens with stress raiser; (d) flat specimens for the study of stress corrosion.

Figure 2 shows one of the possible schemes of loading, viz by the pure rotational bending of a model specimen, when drums with the specimen fastened in them form a doubly supported beam of variable stiffness. It is considered that the stiffness of the drums with the specimen heads clamped in them is much higher than that of the specimen test portion.

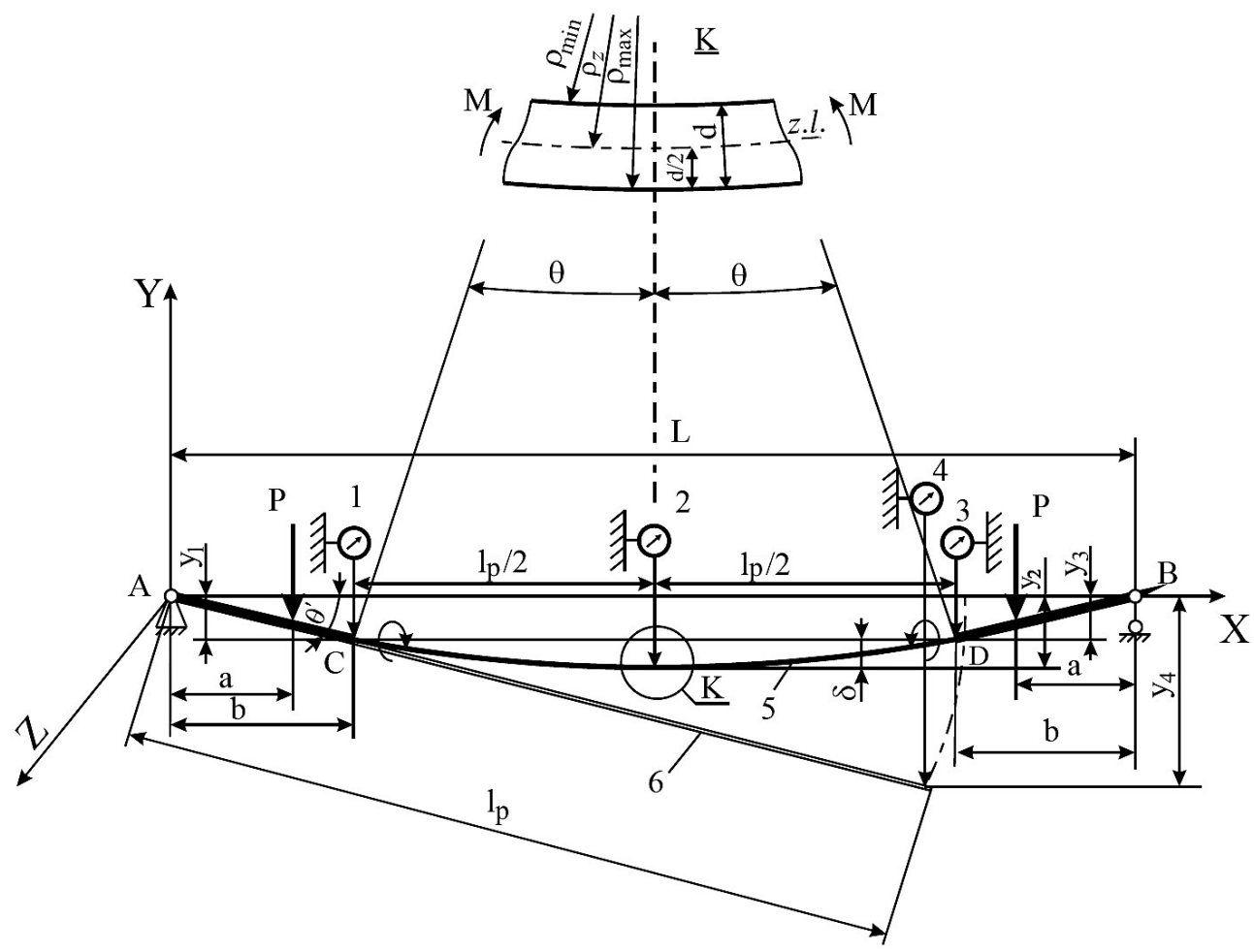

Fig. 2. Scheme of measurement of the displacements of a model specimen loaded by pure rotational bending: (1-4) indicators, (5) specimen, (6) strip; $l_{p}$ is the length of the specimen test portion. To the left drum is rigidly fastened a strip 6 , which can only rotate about the axis $Z$ together with the drum [2].

At the same time, strains were measured according to the scheme in Fig. 2 with needle indicators with scale-division values of 0.001 and $0.01 \mathrm{~mm}$ for the indicators $1-3$ and 4 respectively and by means of spring elements with bonded strain gauges $[2,3]$. 
In the course of cyclic loading, the parameter $y_{4}$, from which the bending deflection of the specimen $\delta$ can be determined using calibration curves, is continuously recorded. The parameters $\delta, l_{p}$, and the radius of curvature $\rho_{\min }$ are interrelated (Fig. 2):

$$
\rho_{\text {min }}=\frac{l_{p}^{2}}{8 \delta}+\frac{\delta}{2} .
$$

Then the extreme fiber strain is

$$
\varepsilon=\frac{d}{2 \rho_{z}}=\frac{1}{2 \rho_{\min } / d+1} .
$$

The analysis of soils was carried out using the potentiometric (ionometric) method for the determination of chlorides content, the $\mathrm{pH}$-metric method for the determination of the acidity of aqueous extract and the turbidimetric method for the determination of sulfates content. Based on the results of a chemical analysis of soil electrolytes in various regions of Ukraine, it has been found that Western Ukraine is characterized by moderately acid soils of chloride type, Polissya by acid and strongly acid soils of chloride and chloride-sulfate type, Central and Eastern Ukraine by highly mineralized neutral and slightly acid soils of chloride and chloride-sulfate type.

To simulate the corrosion of a petroleum and gas pipeline with a damaged protective coating in a soil electrolyte, tests were carried out in six model environments (ME) (Table 2). The choice of acid electrolytes for this investigation was determined by the increased danger of the hydrogen embrittlement of long-operated steels, which involves considerable service risks [4-6]. To predict the corrosion behavior of pipelines, a comprehensive analysis of the internal and external factors that characterize the corrosion rate of the material of pipes in the operating environment is required.

$\mathrm{T}$ a b 1 e 2

Chemical Composition of Solutions for Corrosion Tests

\begin{tabular}{|c|c|c|c|c|}
\hline \multirow{2}{*}{ No. of ME } & \multicolumn{4}{|c|}{ Concentration (mol/l) } \\
\cline { 2 - 5 } & $\mathrm{NaCl}$ & $\mathrm{Na}_{2} \mathrm{SO}_{4}$ & $\mathrm{HCl}$ & $\mathrm{H}_{2} \mathrm{SO}_{4}$ \\
\hline 1 & 0.010 & - & 0.00001 & - \\
\hline 2 & 0.050 & - & 0.00010 & - \\
\hline 3 & 0.100 & - & 0.00100 & - \\
\hline 4 & 0.005 & 0.005 & - & 0.000005 \\
\hline 5 & 0.025 & 0.025 & - & 0.000050 \\
\hline 6 & 0.050 & 0.050 & - & 0.000500 \\
\hline
\end{tabular}

The main characteristic of the rate of corrosive destruction in the case of both partial and uniform corrosion is penetration depth. In both cases, the rate of corrosive destruction is measured in millimeters per year independent of the type of metal or alloy. For the relative characterization of the corrosion behavior of metals, a corrosion resistance scale has been developed.

In the case of uniform corrosion, the mass loss (ML) of the material is determined with the aid of the depth of corrosion penetration (CP, $\mathrm{mm} / \mathrm{year}$ ) from a formula with relation to the unit area. 
The comparison of the amount of maximum corrosion damage, found from the depth of the largest cavities $(\mathrm{mm})$, with the amount of medium corrosion damage, calculated from ML $\left[\mathrm{g} /\left(\mathrm{m}^{2} \cdot \mathrm{h}\right)\right]$, makes it possible to estimate the degree of corrosion nonuniformity. This fact must be taken into account when determining the service life of pipelines since nonuniform corrosion leads to a sharp decrease in their stability through a change in mechanical properties with time [7].

The gravimetric method $[8,9]$ is most commonly used for the assessment of corrosion resistance. It is used in two variants: determination of the increase in specimen mass as a result of formation of corrosion products on the specimen surface and determination of ML after the removal of corrosion products. The second variant is more commonly used due to its universality.

Research Results and Their Discussion. The tests were carried out in the air and different environments (Table 3), which made it possible to study the effect of the concentration of corrosive components on the kinetics of corrosive degradation of pipeline steel. Weighing was performed on a damped analytical balance with a measurement accuracy of $0.00005 \mathrm{~g}$. The acid reaction of the soil gives rise to a number of dangerous processes. In the environments with a $\mathrm{pH}$ of under 5.4, hydrogen depolarization begins to develop, which is accompanied by hydrogen evolution and can cause hydrogen saturation of pipeline steel, hydrogen embrittlement associated with it, and corrosion cracking. These processes are especially dangerous in the case of degraded materials, in whose microstructure voids are formed because of long-term operation; hydrogen can accumulate in these voids, causing thereby a sharp reduction in ductility and a rapid crack propagation, which can give rise to depressurization or even to spontaneous fracture along welds. Therefore, the study of the deformation behavior of pipeline steel in soil acid electrolytes is very important for the determination of hidden service risks $[10,11]$.

T a b 1 e 3

Slope Angles of the Final Portions of Deformation Curves for 19G Steel in MEs

\begin{tabular}{|c|c|c|c|c|c|c||}
\hline \multirow{2}{*}{ No. of ME } & \multicolumn{3}{|c|}{ Non-operated pipe } & \multicolumn{3}{c||}{ 41 years of operation } \\
\cline { 2 - 7 } & $330 \mathrm{MPa}$ & $420 \mathrm{MPa}$ & $510 \mathrm{MPa}$ & $330 \mathrm{MPa}$ & $420 \mathrm{MPa}$ & $510 \mathrm{MPa}$ \\
\hline 7 & 3.055 & 5.92 & 7.02 & 3.865 & 6.386 & 7.881 \\
\hline 8 & 3.512 & 6.138 & 3.918 & 3.706 & 6.538 & 9.601 \\
\hline 9 & 4.502 & 5.219 & 5.997 & 6.502 & 7.219 & 4.612 \\
\hline
\end{tabular}

Acidified Chloride Environments. The first stage of studying the effect of $\mathrm{pH}$ on the deformation behavior of long-operated pipe steel was tested in acidified chloride electrolytes. The intensity of the deformation process increases with the nominal stresses. At the highest load, which is close to ultimate strength, kinks are observed on the creep curve. Characteristically, they are sharper for the degraded material and begin to appear at lower levels of stresses (they are noticeable already at $420 \mathrm{MPa}$ ). It is evident that this deformation behavior can be caused by microcrack propagation, which gives rise to a jump-like increase in strain. Since in degraded steel there are much more accumulated damages, including incipient microcracks, a lower level of nominal stresses is required for their starting. This deformation behavior is confirmed by the results of research carried out earlier at the Ivano-Frankivsk National Technical University of Petroleum and Gas [12-15].

In the ME-7 (see Fig. 3), we observe a typical deformation behavior with increasing rate of deformation in the first stage, which in turn causes an increase in absolute strain and its relative increment, as compared with the 17GS steel [16]. 


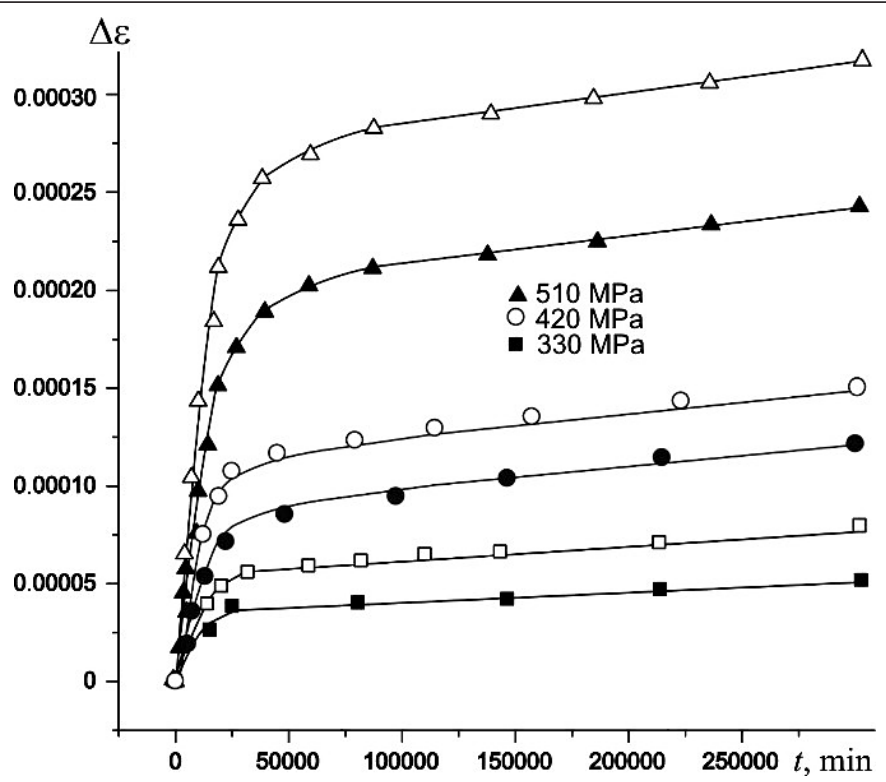

Fig. 3. Deformation kinetics of the pipeline material in the ME-7. (Here and Figs. 4-8: (ם) steel in the as-delivered condition, ( $\square$ ) 41 years of operation.)

The trend of the kinetic curves is monotonic, jump-like changes in strain are not observed. The safety margin of pipelines allows one to successfully continue the operation of pipes made of $19 \mathrm{G}$ steel after the 40 -year period on the condition of regular monitoring of the electrochemical protection parameters and minimization of the irregularity of gas consumption. Greater attention must also be given to the section near the compressor stations, where the risk of damaging the bitumen and bitumen-polymer isolation increases through gas temperature rise [17]. On transition to environments with lower $\mathrm{pH}$ (ME-8 and ME-9), strain jumps caused by the development and propagation of crack-like corrosion defects from the pipe surface begin to arise (Figs. 4 and 5).

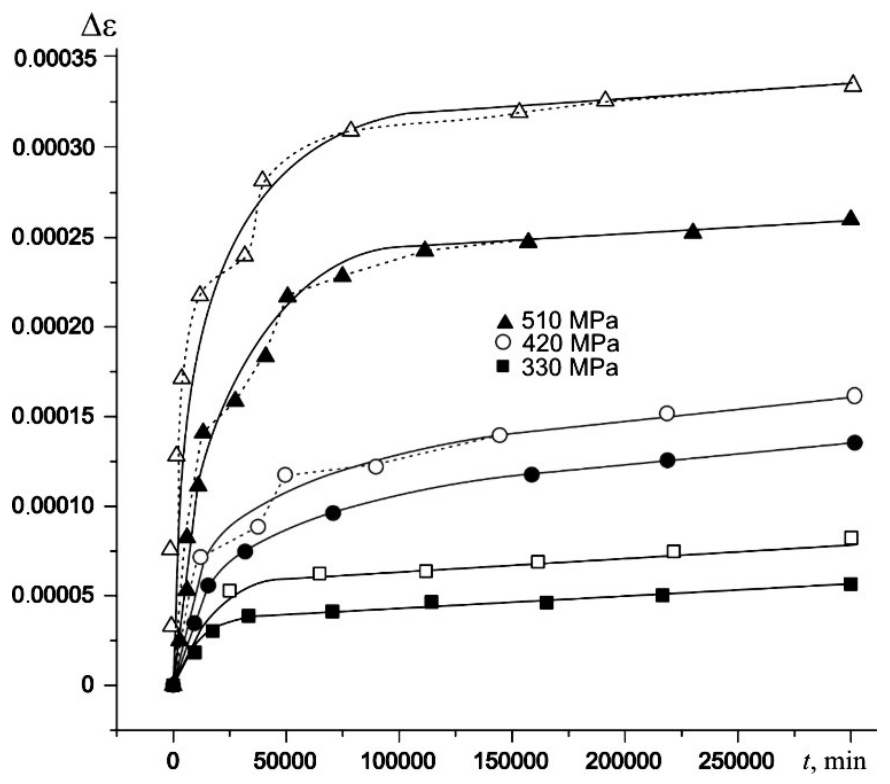

Fig. 4. Deformation kinetics of the pipeline material in the ME-8. 


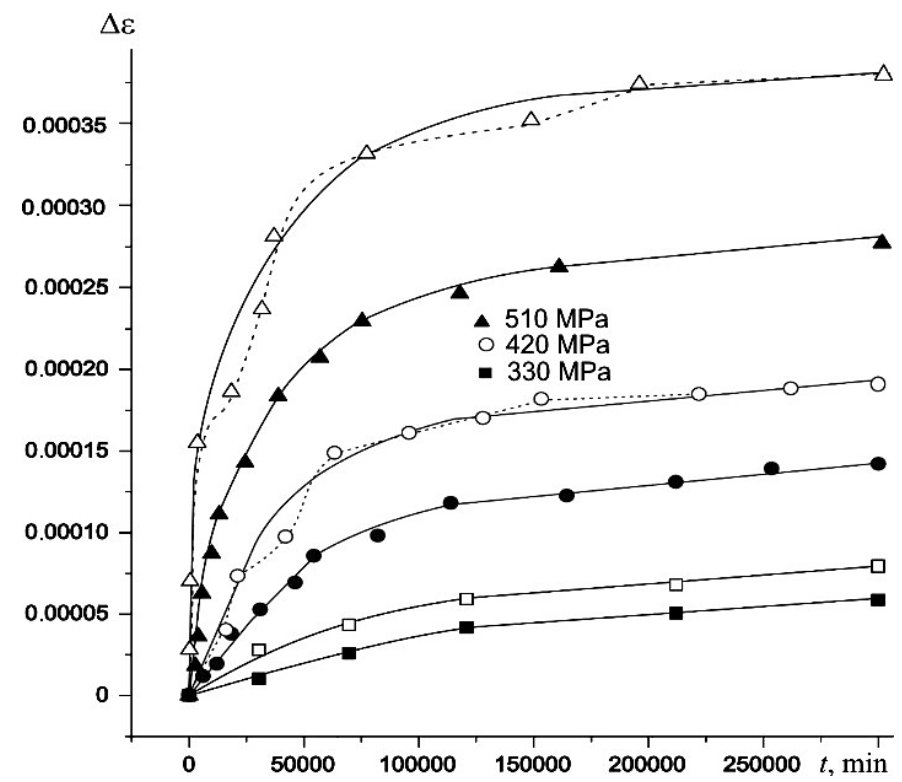

Fig. 5. Deformation kinetics of the pipeline material in the ME-9.

In the ME-8 (pH4), the nature of recorded strain changes makes the greatest contribution to crack formation since we observe the highest rate of progress of corrosion and mechanical processes, which corresponds to the propagation of surface defects.

In the ME-9, we predictably observe larger absolute values and relative strain increments, but the strain fluctuations are smoother, which is due, in our opinion, to the tip blunting of crack-like defects because of metal dissolution at their tip. Analysis of data on the slope angles of the final portions of kinetic curves and their comparison with the results obtained for $17 \mathrm{GS}$ steel indicate an increased danger of progress of corrosion processes and the occurrence of contingencies on the pipelines made of $19 \mathrm{G}$ steel, which have been operated for over 40 years (Table 4). The strain increment is $15-21 \%$.

T a b 1 e 4

Slope Angles of the Final portions of Deformation Curves for 19G Steel in MEs

\begin{tabular}{|c|c|c|c|c|c|c||}
\hline \multirow{2}{*}{ No. of ME } & \multicolumn{3}{|c|}{ Non-operated pipe } & \multicolumn{3}{c||}{ 41 years of operation } \\
\cline { 2 - 7 } & $330 \mathrm{MPa}$ & $420 \mathrm{MPa}$ & $510 \mathrm{MPa}$ & $330 \mathrm{MPa}$ & $420 \mathrm{MPa}$ & $510 \mathrm{MPa}$ \\
\hline 10 & 3.315 & 3.985 & 4.105 & 4.385 & 7.54 & 6.475 \\
\hline 11 & 5.348 & 9.496 & 7.92 & 5.845 & 9.496 & 12.514 \\
\hline 12 & 5.719 & 7.01 & 10.745 & 6.056 & 8.546 & 11.601 \\
\hline
\end{tabular}

Acidified Chloride-Sulfate Environments. The deformation behavior of $19 \mathrm{G}$ steel in acidified chloride-sulfate environments differs only slightly from that in acidified chloride environments. For the ME-10, we observe monotonically increasing kinetics without strain jumps; however, the absolute values of strains and the values of their relative increments increase by $7-14 \%$ as compared with the environments with corresponding $\mathrm{pH}$ level. The decrease in the magnitude of strain jumps is most likely associated with a large number of corrosion damages, because of which the stress concentration at the tips of crack-like defects decreases (unloading effect) (see Figs. 6-8). 


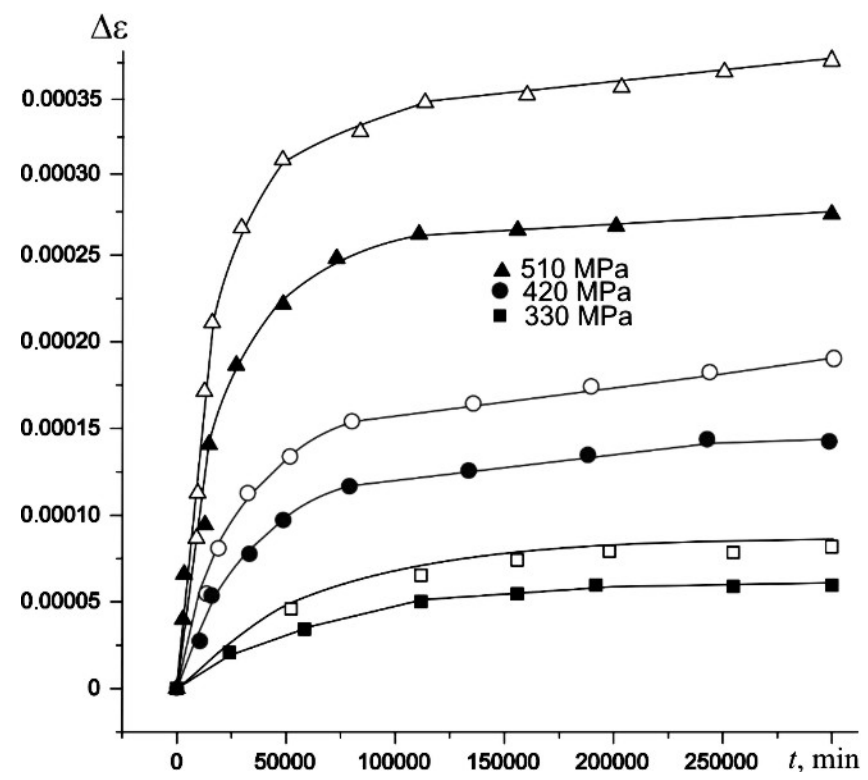

Fig. 6. Deformation kinetics of the pipeline material in the ME-10.

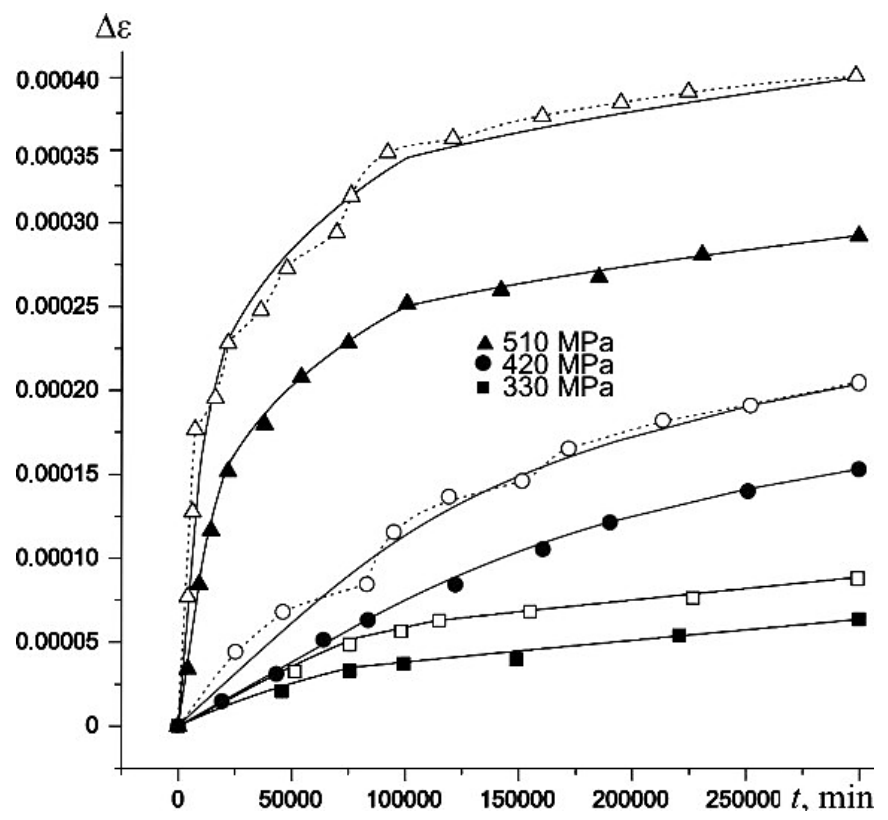

Fig. 7. Deformation kinetics of the pipeline material in the ME-11.

In acidified chloride-sulfate electrolytes, the largest values of strain increment (up to $40 \%$ ) were found for $19 \mathrm{G}$ steel. These results are bound to cause anxiety, especially when the country is in an unstable situation, involving great risks of deliberate harmful actions in high-risk facilities, including main pipelines.

The third stage of the corrosion research was studying corrosive degradation in acidified chloride electrolytes (ME-7-ME-9), which are similar in composition to the ME-1-ME-3 with the only difference that the $\mathrm{pH}$ of the environments was changed by the addition of hydrochloric acid (this variant was chosen to retain the qualitative ionic 


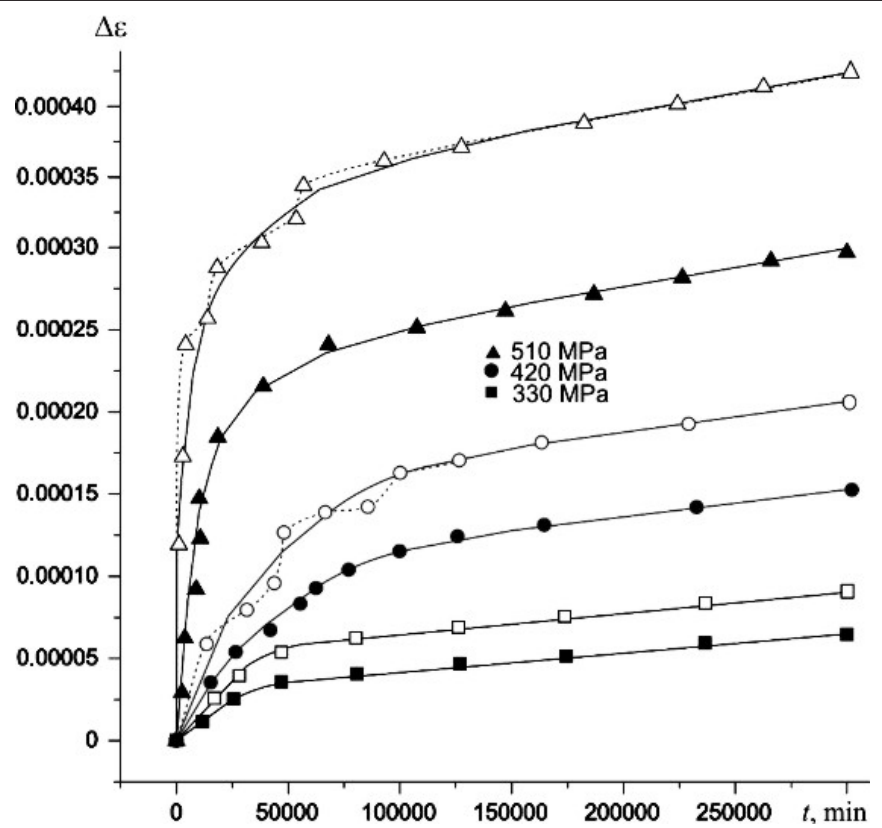

Fig. 8. Deformation kinetics of the pipeline material in the ME-12.

composition of the environment). In the ME-7, ME-8, and ME-9, $\mathrm{pH}$ is 5 , 4, and 3 respectively. This methodological approach was chosen to assess the effect of the environment $\mathrm{pH}$ on the rate and nature of corrosion processes.

It has been found (Fig. 9) that change in the environment $\mathrm{pH}$ has a considerable effect on the nature of corrosive degradation. The change in the rate of general and local corrosion in the elastic region is small, which is attributed to a change in the mechanism of cathodic depolarization from oxygen mechanism to a mixed one. The rate of the hydrogen depolarization process increases with decreasing environment $\mathrm{pH}$, and whereas oxygen depolarization predominates at $\mathrm{pH}$, hydrogen depolarization prevails at $\mathrm{pH} 3$.

A noticeable decrease in local corrosion rate in the ME-9 compared with the ME-3 is associated with this in the first place. At $\mathrm{pH} 3$, the corrosion becomes almost uniform with a slight tendency to localization. This change in corrosion behavior is associated with considerable $\mathrm{H}^{+}$ion mobility, which is much higher than the dissolved oxygen transport rate; therefore, when local concentration galvanic cells (GCs) appear, the depolarization process returns quickly to normal.

An interesting situation is observed in the ME-8. At pH4, the local corrosion rate in this environment differs only slightly from that in the ME-9, though it would seem that the ionic composition in the latter is much more aggressive. This must be accounted for by the mixed mechanism of corrosive degradation (by the simultaneous occurrence of both hydrogen and oxygen depolarization, though the fraction of the former is small).

Because of this mixed mechanism, there remains a space for the formation of local concentration GCs; at the same time, general corrosion occurs rather easily with the aid of mobile $\mathrm{H}^{+}$ions. One of the main causes is also a decrease in the rate of re-passivation (healing) of corrosion defects.

We observe some reduction in localization, but it is not so great as in the ME-9. The lesser intensification of corrosion processes by a mechanical factor is also associated with this since in the case of considerable localization of the process, rather deep corrosion damages, which are initial stress raisers, are formed relatively quickly [18-20]; they cause the formation of a GC "metal outer surface-freshly formed surface (corrosion defect 

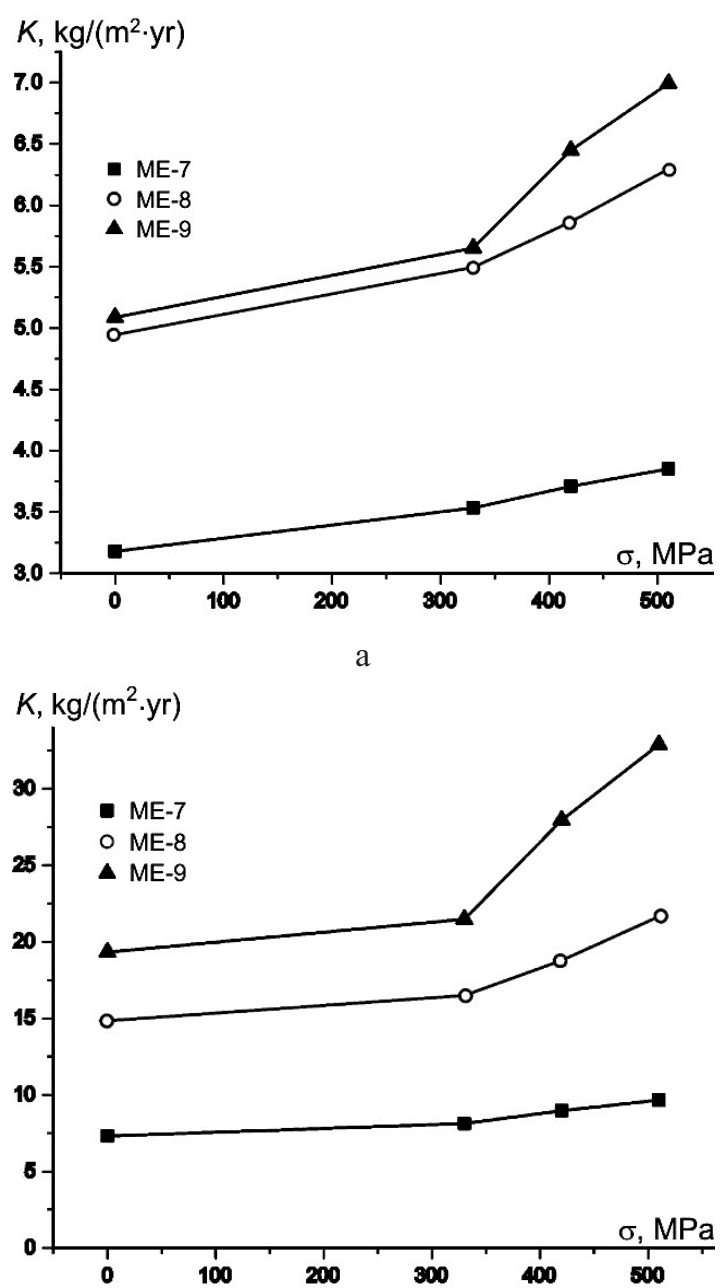

b

Fig. 9. Dependence of general (a) and local (b) corrosion rate in acidified chloride electrolytes on the level of mechanical stresses.

bottom)," the action of which is enhanced by a mechanical factor, facilitating electron escape and metal dissolution.

This synergistic action of the above factors leads to a change in the rate of thinning of the pipe wall. We observe the most dangerous situation for the ME-9, where the rate of wall thinning in the operating load range reaches $0.65 \mathrm{~mm} / \mathrm{yr}$ and can be about $3 \mathrm{~mm} / \mathrm{yr}$ with allowance for the localization of the corrosive degradation process.

It can be concluded that in the case of a change in environment $\mathrm{pH}$, the most appreciable synergistic effect begins in the minimum $\mathrm{pH}$ range, where both general corrosion and the localization of corrosion processes are appreciable. These conclusions are topical first of all for the western regions of Ukraine, where the average age of the pipelines is one of the largest ones in the state; the pipeline steel underwent appreciable degradation and the anticorrosive coatings destruction. Taking into account the considerable salinity and prevalence of acid soils, we can state that there is a considerable potential danger of the occurrence of contingencies, such as depressurization of pipelines because of corrosive degradation. 
When studying the effect of the environmental $\mathrm{pH}$ on the corrosion behavior of pipeline steel in chloride-sulfate electrolytes (ME-10-ME-12), we observe the pattern of corrosion behavior change that is similar to that revealed in acidified chloride electrolytes (Figs. 9-12).

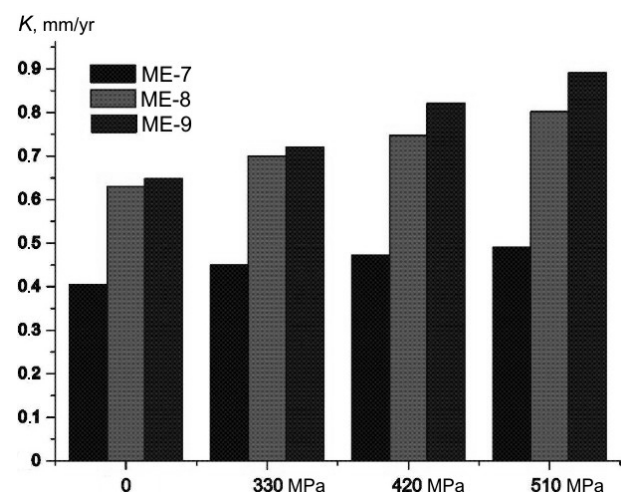

a

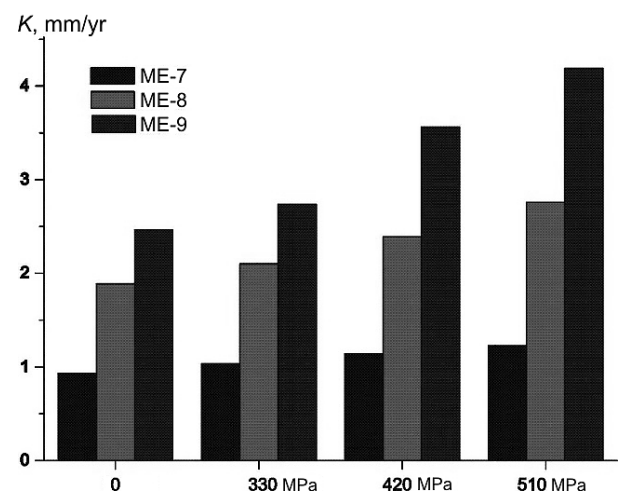

b

Fig. 10. Dependence of pipe wall thinning in the case of uniform (a) and localized (b) corrosion in acidified chloride electrolytes.

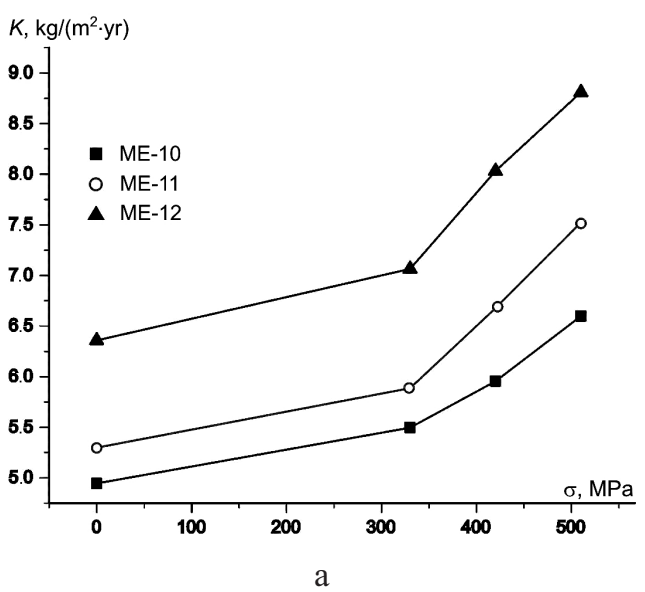

a

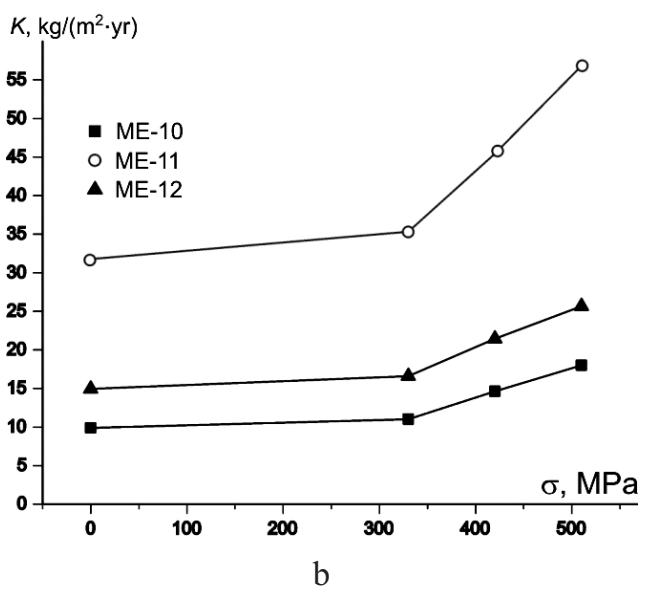

Fig. 11. Dependence of general (a) and local (b) corrosion rate in acidified chloride-sulfate electrolytes on the level of mechanical stresses.

At $\mathrm{pH} 5$, a slight monotonic increase in general and local corrosion rate is observed in the operating load range. However, in the plastic deformation region, we note some acceleration of local corrosion processes and a slight increase in general corrosion rate.

In going from $\mathrm{pH} 3$ to $\mathrm{pH} 4$, a certain increase (of about $10-15 \%$ ) in general corrosion rate and a considerable intensification of localization of corrosion processes have been recorded. An abnormal increase in the local corrosion rate of pipeline steel in chloridesulfate environments at $\mathrm{pH} 4$ (ME-11) has also been recorded.

This corrosion behavior is associated with the observed considerable tendency of corrosion processes to localization in chloride-sulfate environments. In the high load range, local corrosion damages begin to act as stress raisers [21, 22], in which local concentration GCs and GCs with emf, which arises from a potential difference between the metal outer surface and the bottom of corrosion pit or cavity, are formed and accelerate corrosion processes. 


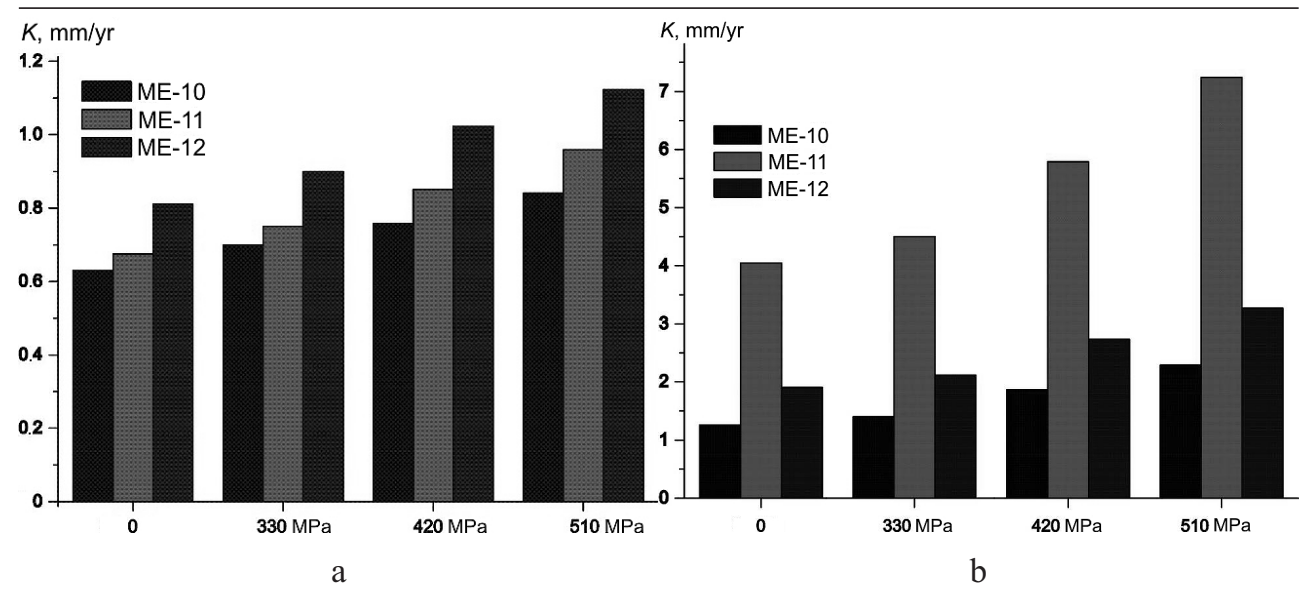

Fig. 12. Dependence of pipe wall thinning in the case of uniform (a) and localized (b) corrosion in acidified chloride-sulfate electrolytes.

At $\mathrm{pH} 3$, a slight increase in general corrosion rate (as compared with the unacidified environment (ME-6) and a considerable decrease in local corrosion rate are observed.

This situation is due, on the one hand, to changes in the mechanism of corrosion processes (as in the case of acidified chloride environments) and, on the other hand, to changes in the found ratio of molar ion concentrations, which causes an enhanced synergism of the action of the corrosion and mechanical factors. This explanation is actually the only possible one since the qualitative ionic composition of the environment, as well as the pipeline material and the applied mechanical stresses remain unchanged.

Conclusions. The effect of in-service degradation on the deformation behavior of the material of gas mains has been studied, and it has been shown that depending on the concentration of the corrosive components of the environment, the strain increment can be up to $20-30 \%$.

It has been found that in soil acid electrolytes, degraded pipeline steel has a tendency to sudden strain jumps, which can cause spontaneous depressurization of the pipeline.

The joint effect of the chemical composition of soil electrolyte and the value of mechanical stresses on the corrosion behavior of the long-operated pipe steels 17GS and $19 \mathrm{G}$ has been studied. It has been found that the pipe steel $19 \mathrm{G}$ is more sensitive to the influence of soil acid electrolytes than 17GS.

1. V. R. Klos, M. Birke, E. Ya. Zhovyns'kyi, et al., "Regional geochemical investigations of Ukrainian soils in the framework of an international project on the geochemical mapping of agricultural and pasture lands of Europe (GEMAS)," Poshuk. Ekol. Geokhim., No. 1, 51-66 (2012).

2. E. I. Kryzhanivs'kyi and L. Ya. Poberezhnyi, "Methodology of studying the deformation and failure of pipeline systems," in: Proc. of the IIIrd Int. Conf. on Fracture Mechanics of Materials and Strength of Structures [in Ukrainian], Lviv (2004), pp. 419-424.

3. E. I. Kryzhanivs'kyi and L. Ya. Poberezhnyi, "Methodological aspects of studying the interrelation between deformation and fracture processes in pipelines," Naft. Gaz. Promysl., No. 5, 33-38 (2002).

4. E. I. Kryzhanivs'kyi and H. M. Nykyforchyn, "Peculiarities of the corrosion and hydrogen degradation of steels of petroleum and gas pipelines and petroleum storage tanks," Fiz.-Khim. Mekh. Mater., No. 2, 11-20 (2011). 
5. E. I. Kryzhanivs'kyi and H. M. Nykyforchyn, "Scattered damage and degradation of the properties of steels of petroleum and gas pipelines," Visn. Ternopil. Nats. Tekhn. Univ., Special issue, Part 1, 30-36 (2011).

6. V. D. Myndyuk, E. R. Dotsenko, and M. O. Karpash, "Peculiarities of the structural degradation of materials of long-operated metallic structures and assessment of the possibility of its prediction in an oil and gas complex," Nauk. Visn. IFNTUNG, No. 2 (28), 91-97 (2011).

7. H. M. Nykyforchyn, O. T. Tsyrul'nyk, D. Yu. Petryna, and M. I. Hredil', "Degradation of steels used in gas main pipelines during their 40-year operation," Strength Mater., 41, No. 5, 501-505 (2009).

8. D. M. Barborak and A. B. William, Method and Apparatus for Measuring Pipeline Corrosion, US Patent No. 5362962 A, Publ. on November 8, 1994.

9. N. G. Chausov, Fracture Kinetics of Metals in the Final Deformation Stages [in Russian], Author's Abstract of the Doctor Degree Thesis (Tech. Sci.), Pisarenko Institute of Problems of Strength, National Academy of Sciences of Ukraine, Kiev (1992).

10. S. P. Vashchyshchak, P. M. Raiter, and A. V. Yavors'kyi, "Analysis of the risks of the safe operation of long-length engineering inctallations and approaches to their assessment," Rozvid. Rozrob. Naft. Gaz. Rodov., No. 2, 54-58 (2011).

11. L. Poberezhnyi, A. Stanets'kyi, and V. Rudko, "Corrosion monitoring of transit gas pipelines," Visn. Ternopil. Nats. Tekhn. Univ., 16, No. 3, 20-26 (2011).

12. L. Ya. Poberezhnui, T. Yu. Pyrig, and A. I. Stanets'kyi, "Effect of the ionic strength of a soil electrolyte on the corrosion rate of the metal of petroleum and gas pipelines," Fiz.-Khim. Mekh. Mater., 2, Special issue No. 8, 620-624 (2010).

13. L. Ya. Poberezhnyi, P. O. Marushchak, and A. I. Stanets'kyi, "Effect of in-service degradation on the load-carrying ability of the material of main pipelines," Fiz.-Khim. Mekh. Mater., 2, Special issue No. 9, 642-646 (2012).

14. L. Ya. Poberezhnyi, A. I. Stanets'kyi, M. S. Polutrenko, and P. O. Marushchak, "Methodology for the establishment of regions of increased corrosion and biocorrosion activity as a component of the comprehensive monitoring of petroleum and gas pipelines," Visn. Skhidnoukr. Nats. Univ., No. 13, 161-166 (2013).

15. P. O. Marushchak, R. T. Bishchak, and I. M. Danylyuk, Crack Resistance of Materials and Structures: Long-Operated Gas Mains [in Ukrainian], Zazaprint, Ternopil (2016).

16. L. Ya. Poberezhnyi and A. I. Stanets'kyi, "Ranking of soils according to the danger of loss of load-carrying ability by pipelines in the late stage of operation," Nauk. Visn. NLTU Ukr., No. 1, 280-286 (2016).

17. Yu. I. Garber, "Efficiency of insulating coatings applied under field conditions," Stroit. Truboprov., No. 7, 21-24 (1992).

18. P. Marushchak, I. Danylyuk, O. Prentkovskis, et al., "Degradation of the main gas pipeline material and mechanisms of its fracture," J. Civ. Eng. Manag., 20, 864-872 (2014).

19. P. Marushchak, S. Panin, I. Danylyuk, et al., "Structural and mechanical defects of materials of offshore and onshore main gas pipelines after long-term operation," Open Eng., 5, No. 1, 365-372 (2015).

20. P. Marushchak, I. Danylyuk, L. Poberezhnyi, et al., "Influence of preliminary deformation on micromechanisms of failure of offshore gas pipeline material," Appl. Mech. Mater., 770, 304-309 (2015). 
21. P. O. Marushchak and I. M. Danylyuk, "Laws governing the deformation of the steel of gas mains after long-term in-service degradation," in: Proc. of the Int. Sci. Readings Dedicated to the Corresponding Member I. A. Oding of the RAS "Mechanical Properties of Modern Structural Materials" (September 4-5, 2014), Baikov Institute of Metallurgy and Materials Science, Russian Academy of Sciences, Moscow (2014).

22. P. Marushchak, S. Panin, F. Stachowicz, et al., "Structural levels of fatigue failure and damage estimation in $17 \mathrm{Mn} 1 \mathrm{Si}$ steel on the basis of multilevel approach of physical mesomechanics," in: Proc. of the Int. Conf. on Advances in Micromechanics of Materials (July 8-11, 2014, Rzeszow, Poland), Rzeszow (2014), pp. 40-42.

Received 01. 09. 2017 